\title{
Experimental Analysis and Comparative Performance of Ti-Based Coatings on Hard- Chrome Plated Stainless Steel
}

\author{
Supakanya KHANCHAIYAPHUM, Charnnarong SAIKAEW, Surasak SURINPHONG
}

\begin{abstract}
Experimental analysis was performed to evaluate the performances of hard-chrome plated stainless steel and TiAISiN and TiCrAlSiN hard coatings deposited on cast stainless steel based on wear experimental data. The wear tests were carried out using a reciprocating wear tester modified from ASTM G133-05.The analysis of variance and other statistical tools were used to explore the influences of coating type, applied load and workpiece surface roughness on the average weight loss values of the workpiece materials. The results showed that coating type, applied load, and workpiece surface roughness and the interactions between coating type and applied load as well as between coating type and workpiece surface roughness were statistically significant at the level of significance of 0.05 . Furthermore, the TiCrAlSiN coating had the highest wear resistance followed by the TiAISiN and the hard-chrome plated stainless steel, respectively.
\end{abstract}

Keywords: ANOVA; coatings; hard chrome; wear test; weight loss

\section{INTRODUCTION}

TiN coatings are extensively employed in various industries to increase the wear resistance and lifetime of machine component [1, 2]. They have limitation of preventing $\mathrm{O}_{2}$ condensation reaction. If $\mathrm{Al}$ and $\mathrm{Cr}$ are added, preventing $\mathrm{O}_{2}$ condensation reaction will increase [3]. TiAlN have been developed to prevent high temperature $\mathrm{O}_{2}$ condensation [4]. However, TiAlSiN has better wear resistance than TiAlN and TiN by adding Si [57]. This technology has lead to development of TiSiN and TiAlSiN to provide preferable protection $\mathrm{O}_{2}$ condensation, wear resistance and mechanical properties [8]. TiAlSiN coated in a vacuum chamber has better mechanical properties and good thermal stability [9]. The coating will increase the wear resistance and hardness if it has a multilayer coating [10].

Generally, Ti-based coatings can be deposited by a variety of techniques such as PVD magnetron sputtering $[11,24]$ and filtered cathodic arc (FCA) which are extensively used processes for hard coatings because of high surface smoothness, quality coatings, coating rate and coating repetitions. TiAlSiN and TiCrAlSiN coatings are developed on the basis of magnetron sputtering [12-14], FCA [15-18], hybrid of sputtering and FCA techniques [19]. In the past decade, wear behaviours of TiAlSiN and TiCrAlSiN deposited on various materials have been studied such as stainless steel (SS) [23], Ni-Cr based alloys [17], tool steel [18] and Ni-based high-temperature alloys [19]. Wear behaviours of the coatings were examined including microstructure, hardness, friction coefficient and wear characteristics by the standard testing apparatuses such as pin-on-flat, pin-on-drum, pin-on-disc and reciprocating ball-on-flat depending on a variety of industrial applications [20].

In this research work, the performances of TiAlSiN and TiCrAlSiN hard coatings deposited on cast stainless steel (SS) were compared with the hard-chrome plated stainless steel (HC) under abrasive wear tests in dry condition. A three-factor factorial design and analysis of variance (ANOVA) were employed to investigate the influences of the HC, TiAlSiN and TiCrAlSiN coatings, the workpiece surface roughness and applied load on wear resistance in terms of weight loss measurements of the workpiece materials.

\section{EXPERIMENTAL PROCEDURE}

The test specimens were the cast stainless steel (SS) with the length of $4 \mathrm{~cm}$ and the width of $1.5 \mathrm{~cm}$. The SS was produced by the lost wax casting process and was machined by turning and milling operations. The specimens were developed for surface finishing employing a vibratory finishing machine with mixed ball burnishing media in different sizes varying from 5 to $8 \mathrm{~mm}$. The chemical composition of the SS included $61.28 \% \mathrm{Fe}$, $20.75 \% \mathrm{Cr}, 6.23 \% \mathrm{Ni}$ and $3.06 \% \mathrm{Cu}$. Improvement of SS surface quality was accomplished through multi-layered depositions with Ti-based materials. TiAlSiN and TiCrAlSiN were coated on the SS by the FCA system (Nanoshield Co., Ltd). The detailed descriptions of TiAlSiN and TiCrAlSiN coatings by the FCA method were stated in the previous work [23].

The hardness of each specimen was measured by a hardness tester (UMIS: model UMIS II) after coating the specimens and before the wear tests. The surface roughness was measured with a standard roughness tester (Mahr: model MarSurf PS1). The specimens were separated into two groups: the average surface roughness $(R a)$ lower than $0.02 \mu \mathrm{m}(R z<0.05 \mu \mathrm{m})$ and the average surface roughness $(R a)$ higher than $0.5 \mu \mathrm{m}(R z>1.5 \mu \mathrm{m})$.

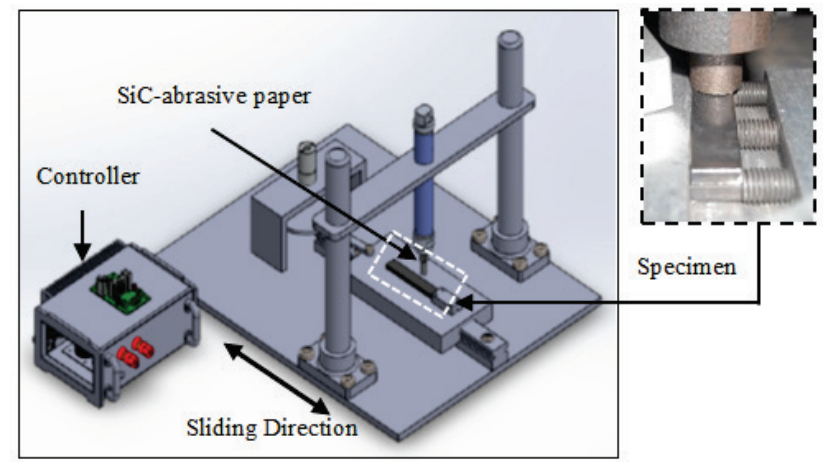

Figure 1 Schematic illustration of the abrasion wear tester [21] 
Wear tests of TiAlSiN, TiCrAlSiN and HC were performed by a reciprocating wear tester modified from ASTM G133-05 as shown in Fig. 1 [21]. The wear tests were performed on a 1000 grit silicon carbide ( $\mathrm{SiC}$ grit\#1000: Struers) and applied load at 5 and $10 \mathrm{~N}$. The oscillating frequency was $1.167 \mathrm{~Hz}(70 \mathrm{rpm})$. The testing time was $100 \mathrm{~min}$ and the length of the forward-backward movement was $15 \mathrm{~mm}$. The weight loss values of all specimens were collected as per three-factor factorial design of experiments. Each treatment combination of coating type, applied load and surafce roughness factors was repeated three times. The thirty-six specimens were weighed using an electronic balance before wear tests. After wear tests, the specimens were weighed again. The weights before and after the wear test of each specimen were used to calculate a weight loss value. A comparison of average weight loss data from the wear tests was performed to identify the statistically significant factors using ANOVA and statistical graphical tools. The model for the three-factor factorial design was expressed as follows:

$$
\begin{aligned}
& y_{i j k l}=\mu+\tau_{i}+\beta_{j}+\delta_{k}+(\tau \beta)_{i j}+(\tau \delta)_{i k}+(\beta \delta)_{j k}+ \\
& +(\tau \beta \delta)_{i j k}+\varepsilon_{i j k l}
\end{aligned}
$$

where $i$ represented the $i$ th level of coating type factor (HC, TiAlSiN and TiCrAlSiN); $j$ expressed the $j$ th level of applied load factor $(5 \mathrm{~N}$ and $10 \mathrm{~N}) ; k$ represented the $k$ th level of workpiece surface roughness factor ( $R a$ of 0.02 and $R a$ of $0.5 \mu \mathrm{m}) ; l$ denoted the $l^{\text {th }}$ replication of each treatment combination. Generally, $y_{i j k l}$ was the observed weight loss value from the wear test, $\mu$ was the overall mean effect, $\tau_{i}$ was the effect of the $i^{\text {th }}$ level of the coating type factor, $\beta_{j}$ was the effect of the $j^{\text {th }}$ level of the applied load factor and $\delta_{k}$ was the effect of the $k^{\text {th }}$ level of the workpiece surface roughness factor. In addition, $(\tau \beta)_{i j}$ was the effect of the two-factor interaction between $\tau_{i}$ and $\beta_{j}$, $(\tau \delta)_{i k}$ was the effect of the two-factor interaction between $\tau_{i}$ and $\delta_{k},(\beta \delta)_{j k}$ was the effect of the two-factor interaction between $\beta_{j}$ and $\delta_{k}$. Similarly, $(\tau \beta \delta)_{i j k}$ represented the threefactor interaction between $\tau_{i}, \beta_{j}$ and $\delta_{k}$ while $\varepsilon_{i j k l}$ was a random error component.

The testing hypotheses about the equalities of all treatment effects of the three factors were defined as follows:

$H_{0}: \tau_{1}=\tau_{2}=\tau_{3}=0$

$H_{1}$ : at least one $\tau_{i}$ not equal to zero

$H_{0}: \beta_{1}=\beta_{2}=0$

$H_{1}$ : at least one $\beta_{j}$ not equal to zero

$H_{0}: \delta_{1}=\delta_{2}=0$

$H_{1}$ : at least one $\delta_{k}$ not equal to zero

The testing hypotheses about the interactions between the two factors were expressed as follows:

$H_{0}:(\tau \beta)_{i j}=0$ for all $i, j$

$H_{1}$ : at least one $\left.\tau \beta\right)_{i j}$ not equal to zero

$H_{0}:(\tau \delta)_{i k}=0$ for all $i, k$

$H_{1}$ : at least one $(\tau \delta)_{i k}$ not equal to zero

$H_{0}:(\beta \delta)_{j k}=0$ for all $j, k$

$H_{1}$ : at least one $(\beta \delta)_{j k}$ not equal to zero
Similarly, the testing hypothesis about the interaction of the three factors was defined as:

$H_{0}:(\tau \beta \delta)_{i j k}=0$ for all $i, j, k$

$H_{1}$ : at least one $(\tau \beta \delta)_{i j k}$ not equal to zero

\section{RESULTS AND DISCUSSION}

Tab. 1 illustrates the experimental results of weight loss values of each treatment combination after carrying out the wear test. The HC plated specimens had the highest weight loss values followed by TiAlSiN and TiCrAlSiN, respectively. Generally, it was found that most weight loss values after carrying out the wear experiments using the applied load of $5 \mathrm{~N}$ were lower than those after carrying out the experiments using the applied load of $10 \mathrm{~N}$ regardless of coating type. In addition, most weight loss values after performing the wear experiments using the workpiece surface roughness of $0.5 \mu \mathrm{m}$ were higher than those after carrying out the experiments using the workpiece surface roughness of $0.02 \mu \mathrm{m}$. On the other hand, after carrying out the experiments using the applied load of $10 \mathrm{~N}$, the weight loss values of TiCrAlSiN coated specimens were different. It showed that the coating material and the workpiece surface roughness indicated interactions. However, the ANOVA and the statistical graphical tools were useful approaches for investigating the effects of the factors on the average weight loss values.

Table 1 Experimental result for weight loss

\begin{tabular}{|c|c|c|c|c|}
\hline \multicolumn{2}{c}{ Table 1 Experimental result for weight loss } \\
\hline \multirow{2}{*}{ Coating type } & \multicolumn{2}{|c|}{ Applied load of 5 N } & \multicolumn{2}{c|}{ Applied load of 10 N } \\
\cline { 2 - 5 } & $R a=0.02$ & $R a=0.5$ & $R a=0.02$ & $R a=0.5$ \\
\hline \multirow{3}{*}{$\mathrm{HC}$} & 0.0695 & 0.0972 & 0.1113 & 0.1314 \\
& 0.0803 & 0.0935 & 0.0991 & 0.1357 \\
& 0.0745 & 0.1070 & 0.1027 & 0.1425 \\
\hline \multirow{3}{*}{ TiAlSiN } & 0.0351 & 0.0472 & 0.0495 & 0.0581 \\
& 0.0324 & 0.0456 & 0.0522 & 0.0593 \\
& 0.0346 & 0.0452 & 0.0518 & 0.0607 \\
\hline \multirow{3}{*}{ TiCrAlSiN } & 0.0236 & 0.0311 & 0.0398 & 0.0413 \\
& 0.0278 & 0.0305 & 0.0384 & 0.0401 \\
& 0.0245 & 0.0297 & 0.0388 & 0.0421 \\
\hline
\end{tabular}

The model adequacy should be checked before carrying out the analysis and interpretations from the ANOVA. The primary diagnostic tool is residual analysis [22]. Fig. 2a presents normal probability plot of residuals for the weight loss values from the wear experiments. If the residuals are normally distributed, the plot will look like a straight line. The trend of the normal probability plot bent down marginally on the right side and upward moderately on the left side. Generally, the normal probability plot of residuals did not indicate a violation of the assumption of normality, although some residuals on the right and the left sides slightly bent down.

A plot of residuals versus fitted (predicted) values is commonly used to perform a nonconstant variance checking. If the model is adequate and the assumption is satisfied, the residuals should be considered structureless. The residuals should be independent to any other factors including the predicted response. If the plot looks like a megaphone, nonconstant variance arises [22]. Fig. 2b does not illustrate a violation of the assumption of nonconstant variances.

The plot of residuals versus run number is used to check the assumption of independence. The experimental 
observations are not independent if the plot exhibits a pattern such as sequence of positve and negative residuals [22]. Fig. 2c exhibits the residuals and the run order of data collection for the weight loss values. The plot did not present the violation of the independence assumption. Fig. $2 \mathrm{~d}$ displays the relationsip between the experimental observations (actual) and the predicted values. The plot is used to examine whether the statistical model fits to the
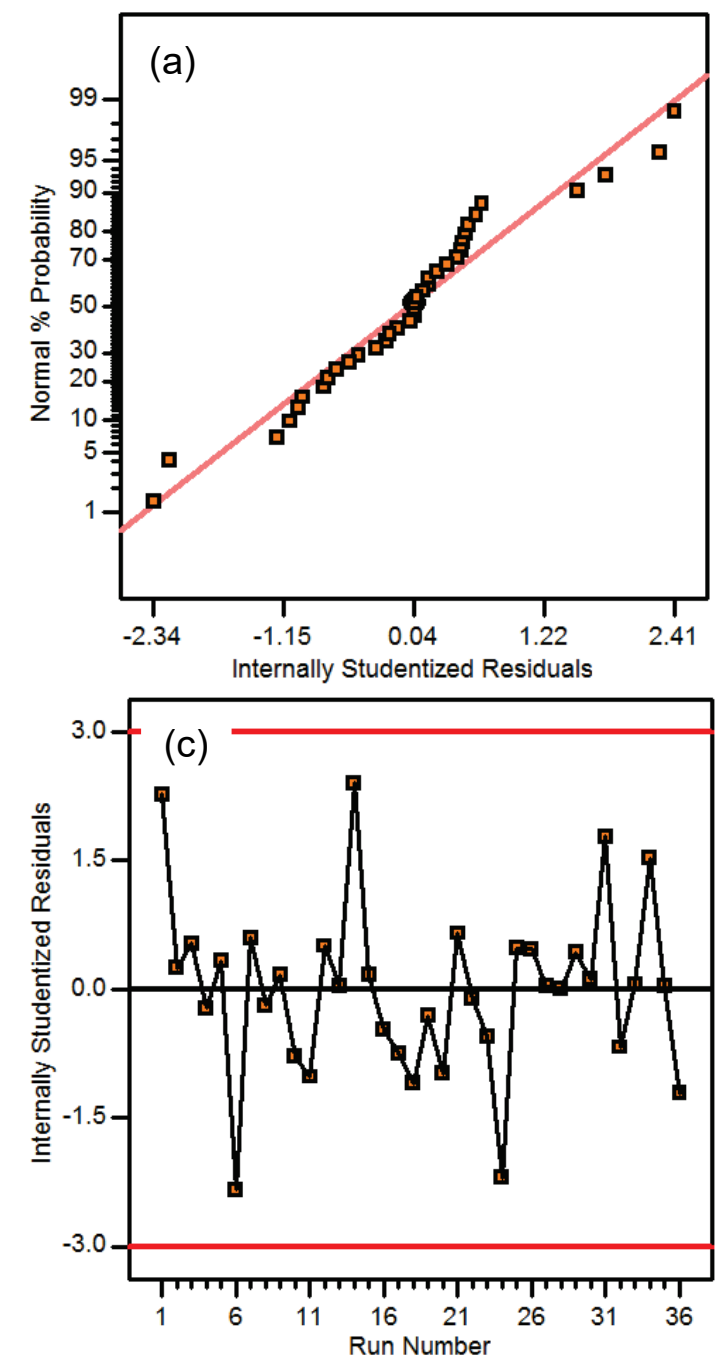

experimental observations and the model can be used to predict the response values. The plot indicated that most of the weight loss values lay in a straight line. This implied that the three-factor factorial model fitted to the experimental observations and the model could be used to predict the weight loss values very well for the wear experiments.
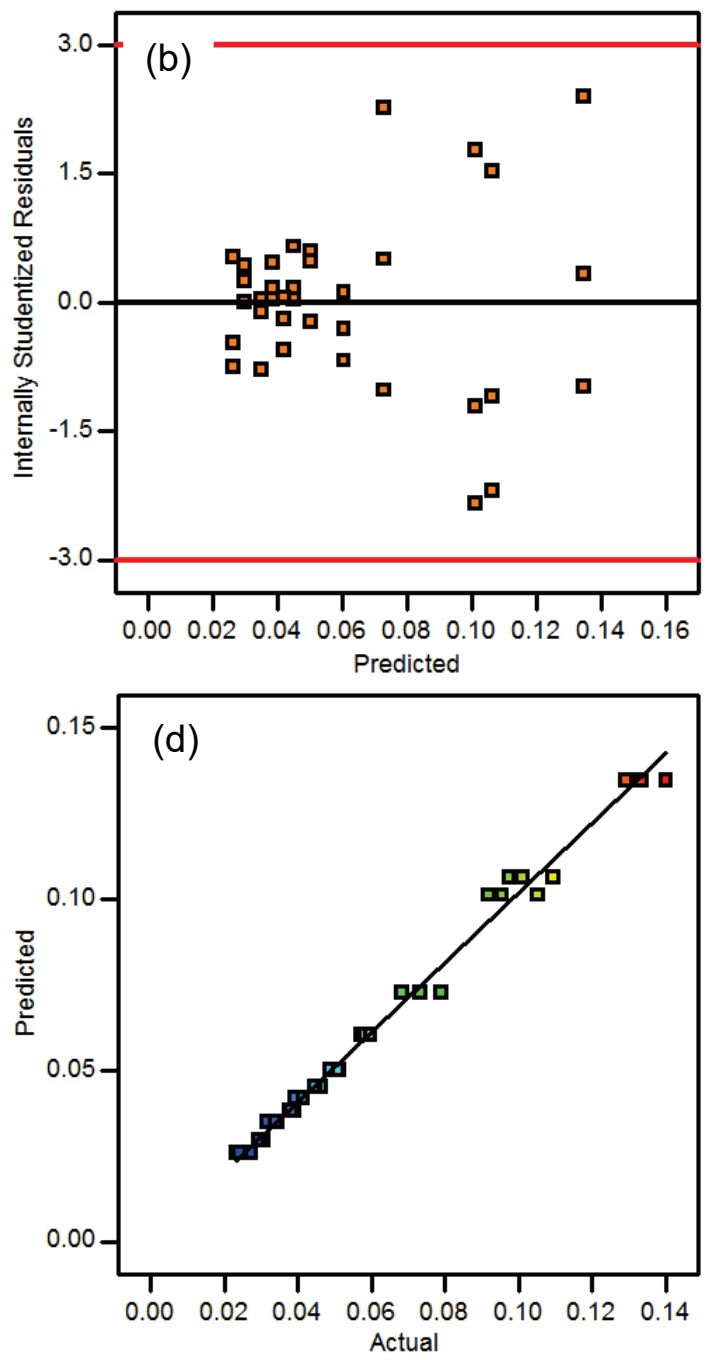

Figure 2 Residuals plot of weight loss (a) normal probability plot of residuals, (b) plot of residuals versus predicted values, (c) plot of residuals versus run number and (d) plot of experimental observations and predicted values

Table 2 The ANOVA table for results for weight loss

\begin{tabular}{|c|c|c|c|c|c|c|}
\hline Source of variation & Sum of squares & Degree of freedom & Mean square & $F$-value & $p$-value & $\%$ contribution \\
\hline Model & 0.04043 & 8 & 0.00505 & 349.62 & $<0.0001$ & \\
\hline$A$-Coating type & 0.03279 & 2 & 0.01639 & 1145.19 & $<0.0001$ & 81.10 \\
\hline$B$-Load & 0.00371 & 1 & 0.00371 & 259.21 & $<0.0001$ & 9.18 \\
\hline$C-R a$ & 0.00177 & 1 & 0.00177 & 123.51 & $<0.0001$ & 4.38 \\
\hline$A B$ & 0.00079 & 2 & 0.00040 & 27.64 & $<0.0001$ & 1.95 \\
\hline$A C$ & 0.00098 & 2 & 0.00049 & 34.31 & $<0.0001$ & 2.42 \\
\hline Residual & 0.00039 & 27 & 0.00001 & & & \\
\hline Lack-of-fit & 0.00006 & 3 & 0.00002 & 1.52 & 0.2349 & \\
\hline Pure error & 0.00032 & 24 & 0.00001 & & & \\
\hline Total & 0.04043 & 35 & & & & \\
\hline
\end{tabular}

The effects of factors (coating type, applied load and workpiece surface roughness) and interactions among the factors on the average weight loss were investigated using ANOVA. Tab. 2 shows that the $F$-value of the model was 349.62 with very small $p$-value. The coefficient of determination $\left(R^{2}\right)$ defined as the ratio of the explained variation to the total variation and was a measure of the degree of fit. The $R^{2}$ was 0.9904 . The adjusted $R^{2}$ and predicted $R^{2}$ were 0.9876 and 0.983 , respectively. The difference between the adjusted $R^{2}$ and predicted $R^{2}$ was less than 0.2 indicating a good model adequacy. Furthermore, the lack-of-fit value was used to measure the 
variation of weight loss values around the fitted model. If the model fits the data well, the lack-of-fit value will not be statistically significant [22]. The $F$-value and the $p$ value for the lack-of-fit test were 1.52 and 0.2349 , respectively. It was not statistically significant at the level of significance of 0.05 indicating a good model. Tab. 2 also shows the sources of variation with the $p$-values less than 0.05 , which are considered to have the statistically significant contributions to the average weight loss. The

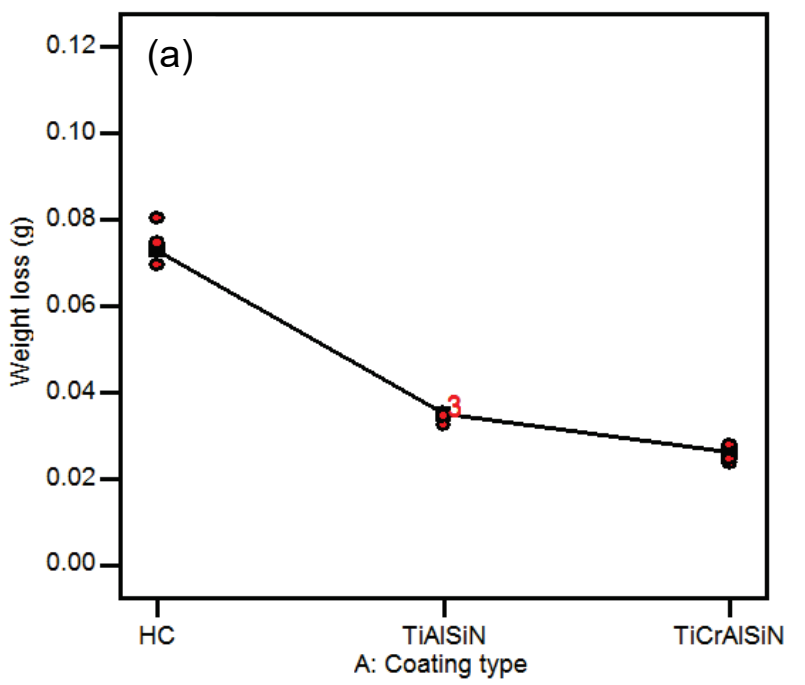

ANOVA results for reduced model by selecting the statistically significant terms with the level of significance of 0.05 indicated that the most statistically significant factor affecting the average weight loss was coating type, which explained the largest contribution accounting for $81.1 \%$ of the total variability. The applied load, workpiece suface roughness, interaction of coating type and applied load, and interaction of coating type and workpiece surface roughness had much lower contribution levels.
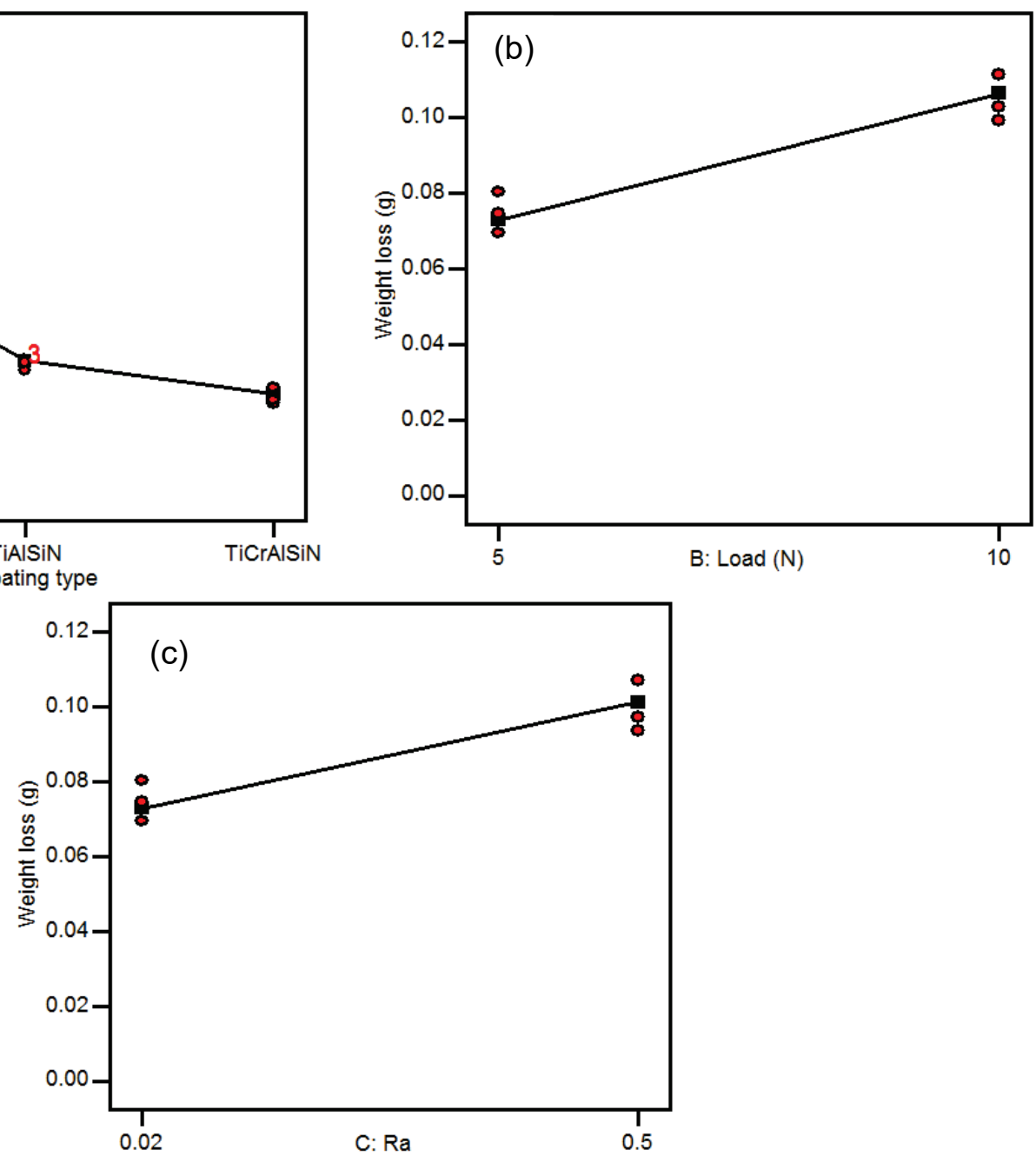

Figure 3 Main effect plots of weight loss for (a) coating type (b) applied load and (c) workpiece surface roughness
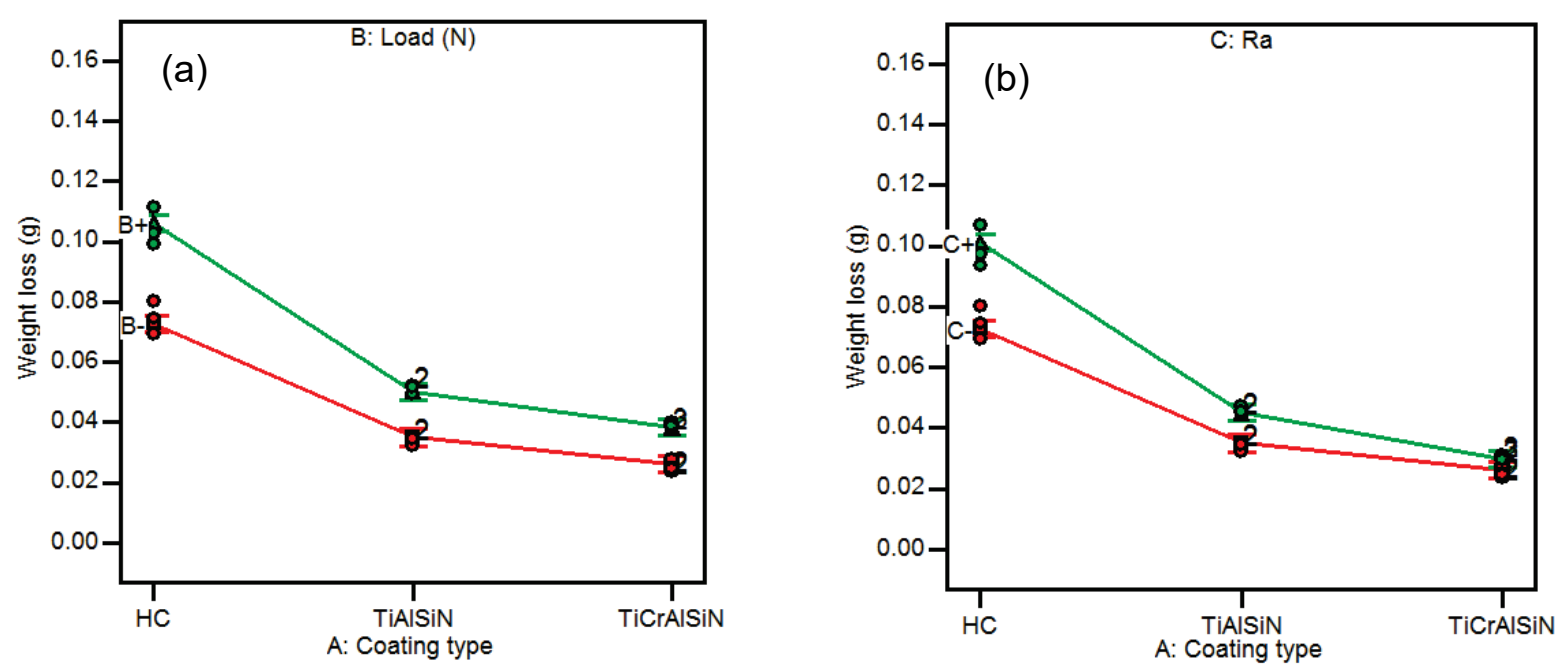

Figure 4 Interaction effect plots of weight loss between (a) coating type and applied load and (b) coating type and workpiece surface roughness 
This study used a main effect plot and an interaction effect plot to evaluate and compare the relative strength of the influences across the three factors. Main effect plot of the average weight loss values at all levels of each factor was constructed in order to assess the average weight loss values changing across the levels of a factor. Fig. 3 illustrates the main effect plots of weight loss for the three factors. Fig. 3a indicates that the weight loss of hard chrome plated-stainless steel was the highest with the maximal value of $0.08 \mathrm{~g}$ whereas the weight loss of TiCrAlSiN coating material was the lowest. Fig. 3b exhibits the effect of applied load on average weight loss values during the wear tests. The weight loss decreased when the applied load was at 5 N. Similarly, Fig. 3c also reveals that the weight loss decreased if the workpiece surface roughness of $0.02 \mu \mathrm{m}$ was used to carry out the wear experiments. Although the ANOVA in Tab. 2 and analysis results from the main effect plots indicated the statistical significances of the influences of the three factors on the average weight loss values, interaction effect plots were the most useful tools to evaluate the effects of the three factors on the average weight loss values.

Interaction effect plot is one of the simplest and powerful graphical tools used to determine whether at least two factors are interacting or not [22]. There is interaction between the factors if the two lines in the interaction effect plot are non-parallel. This indicates that the change in the average response from low level to high level of a factor relies upon the level of another factor. If the degree of departure from being parallel is higher, the interaction effect will be stronger. Fig. 4a illustrates the interaction effect plot between the coating type and applied load. The plot showed that the effects of the coating type at the two levels of applied load on average weight loss values were different. In addition, the effects of applied load at the three levels of coating type were different. Similarly, the results from the ANOVA indicated that the interaction between coating type and applied load was significant at the level of significance of 0.05 . The coating type of TiCrAlSiN exhibited the minimum weight loss when the applied load was kept at 5 N. Fig. $4 \mathrm{~b}$ also showed that the coating type of TiCrAlSiN provided lower weight loss values when the workpiece surface roughness of $0.02 \mu \mathrm{m}$ was used to carry out the wear tests. This confirmed that wear resistance increased with decreasing surface roughness of the coated materials. Furthermore, hardness of the coatings should be evaluated. The average hardness values of $\mathrm{HC}$, TiAlSiN and TiCrAlSiN were approximately $8.9 \mathrm{GPa}, 30.8 \mathrm{GPa}$ and 29.6 GPa, respectively. The hardness values of TiAlSiN and TiCrAlSiN were not significantly different. More statistical analysis for wear resistance of these materials should be further studied. Moreover, the optimal settings for wear resistant improvement should be investigated using graphical plot.

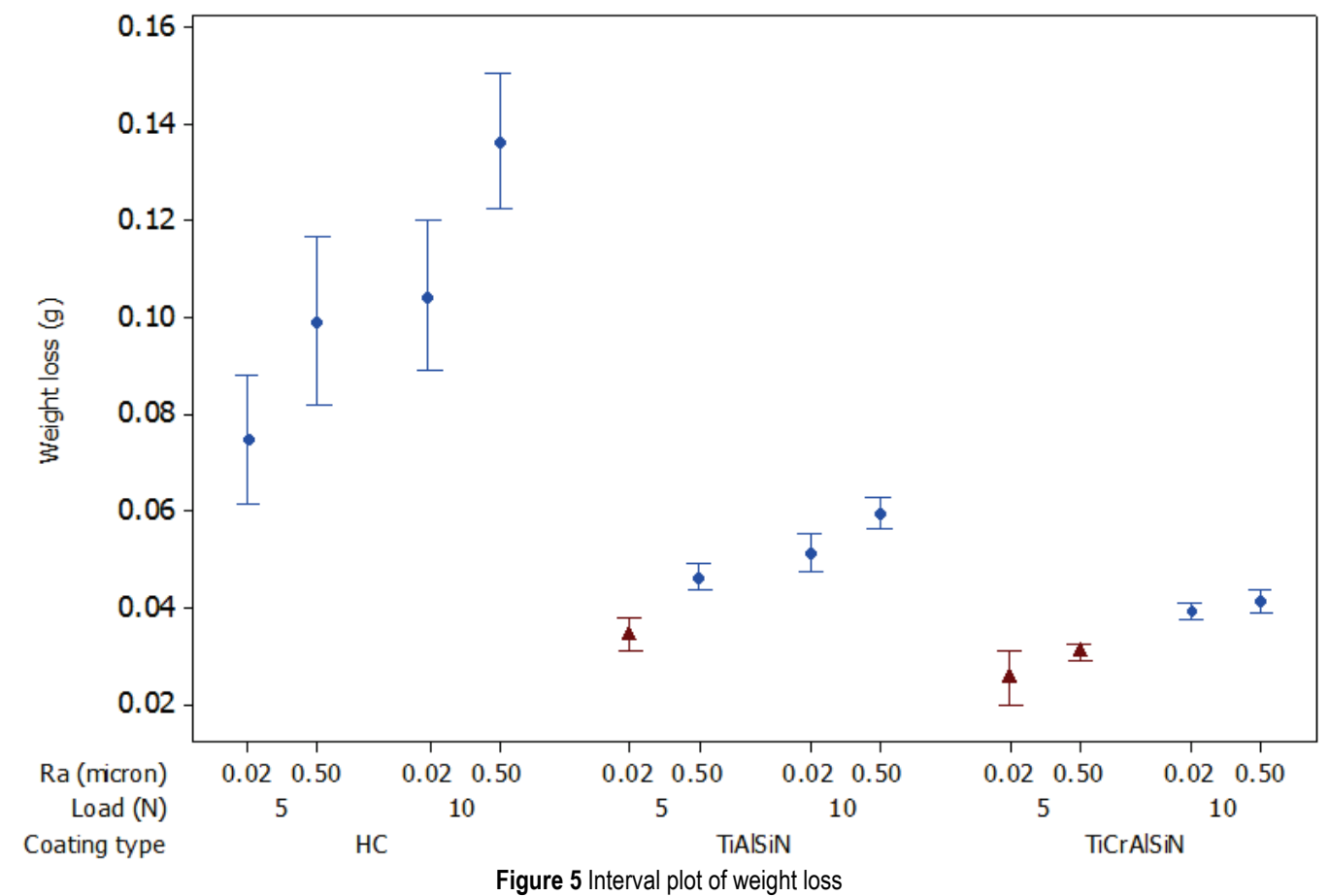

The $95 \%$ confidence interval plot is used to present average response and confidence interval for one or more factors [22]. This plot illustrates both a measure of central tendency (i.e., average response) and variability of the data (i.e., 95\% confidence interval). Fig. 5 depicts 95\% confidence interval plot of the weight loss values of $\mathrm{HC}$, TiAlSiN and TiCrAlSiN with different applied loads and workpiece surface roughness values. The results clearly indicated that the average weight loss values of $\mathrm{HC}$ were higher than those of TiAlSiN and TiCrAlSiN when carrying out wear tests at different applied loads and workpiece surface roughness values. Moreover, the variations of weight loss values of $\mathrm{HC}$ were larger than those of TiAlSiN and TiCrAlSiN because the surface after $\mathrm{HC}$ plating allowed $\mathrm{Cr}$ atoms to be consistently filled in the surface cavities causing substantially different weight loss values [23]. On the other hand, the averages and variations of weight loss values for TiAlSiN and TiCrAlSiN were not significantly different. Some interval plots of the weight loss values of TiAlSiN and TiCrAlSiN exhibited overlapping. The 95\% confidence intervals with overlapping implied that the difference in averages among 
wear testing conditions was statistically insignificant at the level of significance of 0.05 . Hence the analyses suggested that the suitable operating conditions for wear resistant improvement were proposed as follows: 1) using the coating type of TiAlSiN with the workpiece surface roughness of $0.02 \mu \mathrm{m}$ by carrying out the wear experiments at the applied load of $5 \mathrm{~N}, 2$ ) the coating type of TiCrAlSiN with the workpiece surface roughness of $0.02 \mu \mathrm{m}$ by performing the wear tests at the applied load of $5 \mathrm{~N}$ and 3) the coating type of TiCrAlSiN with the workpiece surface roughness of $0.5 \mu \mathrm{m}$ by carrying out the wear tests at the applied load of $5 \mathrm{~N}$.

\section{CONCLUSION}

This research work investigated the performances of TiAlSiN and TiCrAlSiN coatings obtained by the FCA process compared to the hard-chrome plated stainless steel under the reciprocating wear tests in dry condition. A three-factor factorial design was used to prepare wear tests of the three materials with different applied loads and workpiece surface roughness values. The ANOVA was employed to investigate the influences of coating types, workpiece surface roughness and applied load on average weight loss values of the coatings from the wear tests. The findings of this study could be summarized as follows:

- $\quad$ The coating type, applied load and workpiece surface roughness were statistically significant at the level of significance of 0.05 .

- $\quad$ The interaction between coating type and applied load was statistically significant at the level of significance of 0.05 .

- The interaction between coating type and workpiece surface roughness was statistically significant at the level of significance of 0.05 .

- If the workpiece surface roughness of $0.02 \mu \mathrm{m}$ with the applied load of $5 \mathrm{~N}$ was used to carry out the wear tests, TiAlSiN and TiCrAlSiN coated specimens exhibited the lowest weight loss values.

- TiCrAlSiN coated specimens revealed higher wear resistance if the workpiece surface roughness of 0.5 $\mu \mathrm{m}$ with the applied load of $5 \mathrm{~N}$ was used to perform the wear tests.

- Wear resistance increased with increasing hardness of the coated materials.

\section{Acknowledgement}

The authors acknowledge funding supports from the Office of the Higher Education Commission of Thailand and the Thailand Research Fund (TRF) under the Grant No. RSA 5980025.

\section{REFERENCES}

[1] Santecchia, E., Hamouda, A. M. S., Musharava, F., Zalnezhad, E., Cabibbo, M., \& Spigarelli, S. (2015). Wear resistance investigation of titanium nitride-based coatings. Ceramic International, 41, 10349-10379. https://doi.org/10.1016/j.ceramint.2015.04.152

[2] Nunes, V., Silva, J. G., Andrade, M. F., Alexandre, R., \& Baptista, A. P. M. (2017). Increasing the lifespan of highpressure diecast molds subjected to severe wear. Surface and Coatings Technology, 332, 319-331. https://doi.org/10.1016/j.surfcoat.2017.05.098

[3] Sun, K. K., Pham, V. V., \& Jae, W. L.(2003). Deposition of superhard nanolayered TiCrAlSiN thin films by cathodic arc plasma deposition. Journal of Crystal Growth, 252, 257-264. https://doi.org/10.1016/j.surfcoat.2008.06.020

[4] Rodríguez-Baracaldoa, R., Benitob, J. A., Puchi-Cabrerad, E. S., \& Straiad, M. H. (2007).High temperature wear resistance of (TiAl)N PVD coating on untreated and gas nitrided AISI H13 steel with different heat treatments. Wear, 262, 380-389. https://doi.org/10.1016/j.wear.2006.06.010

[5] Çalışkan, H., Kurbanoğlu, C., Panian, P., Čekada, M., \& Kramar, D. (2013). Wear behavior and cutting performance of nanostructured hard coatings on cemented carbide cutting tools in hard milling. Tribology International, 62, 215-222. https://doi.org/10.1016/j.triboint.2013.02.035

[6] Faga, M. G., Gautier, G., Calzavarini, R., Perucca, M., Boot, E. A., Cartasegna, F., \& Settineri, L. (2007).AlSiTiN nanocomposite coatings developed via arc cathodic PVD: evaluation of wear resistance via tribological analysis and high speed machining operations. Wear, 263, 1306-1314. https://doi.org/10.1016/j.wear.2007.01.109

[7] Yu, D. H., Wang, C. Y., Cheng, X. L., \& Zhang, F. L. (2009).Microstructure and properties of TiAlSiN coatings prepared by hybrid PVD technology. Thin Solid Films, 517, 4950-4955. https://doi.org/10.1016/j.tsf.2009.03.091

[8] Sun, K. K. \& Vinh, V. L. (2010).Cathodic arc plasma deposited TiAlSiN thin films using an Al-15 at.\% Si cathode. Thin Solid Films, 518, 7483-7486. https://doi.org/10.1016/j.tsf.2010.05.029

[9] Veprek, S., Männling, H. D., Jilek, M., \& Holubar, P. (2004). Avoiding the high-temperature decomposition and softening of $\left(\mathrm{Al}_{1-\mathrm{x}} \mathrm{Ti}_{\mathrm{x}}\right) \mathrm{N}$ coatings by the formation of stable superhard nc-( $\left.\mathrm{Al}_{1-\mathrm{x}} \mathrm{Ti}_{\mathrm{x}}\right) \mathrm{N} / \mathrm{a}-\mathrm{Si}_{3} \mathrm{~N}_{4}$ nanocomposite. Materials Science and Engineering: A, 366, 202-205. https://doi.org/10.1016/j.msea.2003.08.052

[10] Sui, X., Li, G., Qin, X., Yu, H., Zhou, X., Wang, K., \& Wang, Q. (2016). Relationship of microstructure, mechanical properties and titanium cutting performance of TiAlN/TiAlSiN composite coated tool. Ceramic International, 42, 7524-7532. https://doi.org/10.1016/j.ceramint.2016.01.159

[11] Major, L. (2015).The wear mechanisms description of multilayer coatings, performed by transmission electron microscopy-an overview of the own research work. Archives of Metallurgy and Materials, 60(3B), 2319-2326. https://doi.org/10.1515/amm-2015-0379

[12]Andrade, M. F. C., Martinho, R. P., Silva, F. J. G., Alexandre, R. J. D., \& Baptista, A. P. M. (2009). Influence of the abrasive particles size in the micro-abrasion wear tests of TiAlSiN thin coatings. Wear, 267, 12-18. https://doi.org/10.1016/j.wear.2008.12.114

[13] Barshilia, H. C., Shashidhara, M. G., Ramakrishna, R., \& Rajam, K. S. (2010). Deposition and characterization of TiAlSiN nanocomposite coatings prepared by reactive pulsed direct current unbalanced magnetron sputtering. Applied Surface Science, 256, 6420-6426. https://doi.org/10.1016/j.apsusc.2010.04.028

[14] Yuan, Y., Qin, Z., Yu, D., Wang, C. Y., Sui, J., Lin, H., \& Wang, Q. (2017). Relationship of microstructure mechanical properties and hardened steel cutting performance of TiSiNbased nanocomposite coated tool. Journal of Manufacturing Processes. 28, 399-409. https://doi.org/10.1016/j.jmapro.2017.07.007

[15] Kim, S. K., Vinh, P. V., \& Lee, W. J. (2008). Deposition of superhard nanolayered TiCrAlSiN thin films by cathodic arc plasma deposition. Surface \& Coatings Technology, 202, 5395-5399. https://doi.org/10.1016/j.surfcoat.2008.06.020

[16] Nguyen, T. D., Kim, S. K., \& Lee, D. B. (2009). Hightemperature oxidation of nano-multilayered TiCrAlSiN thin films in air. Surface \&Coatings Technology, 204, 697-704. 
https://doi.org/j.surfcoat.2009.09.008

[17] Tuchida, K., Wathanyu, K., \& Surinphong, S. (2012). Thermal oxidation behavior of TiCrAlSiN and AlCrTiN films on hastelloyX. Advance Materials Research, 486, 400405. https://doi.org/10.4028/www.scientific.net/AMR.486.400

[18] Martinho, R. P.,Andrade, M. F. C., Silva, F. J. G., Alexandre, R. J. D., \& Baptist, A. P. M. (2009). Micro-abrasion wear behaviour of TiCrAlSiN nanostructured coatings. Wear, 267, 1160-1165. https://doi.org/10.1016/j.wear.2008.12.063

[19] He, N., Li, H., Ji, L., Liu, X., Zhou, H., \& Chen, J. (2016). High temperature tribological properties of TiAlSiN coatings produced by hybrid PVD technology.Tribology International, 98, 133-143. https://doi.org/10.1016/j.triboint.2016.02.034

[20] Kennedy, D. M. \& Hashmi, M. S. J. (1998). Methods of wear testing for advanced surface coatings and bulk materials. Journal of Material Processing Technology, 77, 246-253. https://doi.org/10.1016/S0924-0136(97)00424-X

[21] Srisattayakul, P., Saikaew, C., Wisitsoraat, A., \& Phokharatkul, D. (2017). Reciprocating two-body abrasive wear behavior of DC magnetron sputtered Mo-based coatings on hard-chrome plated AISI 316 stainless steel. Wear, 378-379, 96-105.

https://doi.org/10.1016/j.wear.2017.01.005

[22] Montgomery, D. C. (2005). Design and Analysis of Experiments, $6^{\text {th }}$ Ed., John Wiley \& Sons, New York.

[23] Khanchaiyaphum, S., Saikaew, C., Wisitsoraat, A., \& Surinphong, S. (2017). Wear behaviours of filtered cathodic arc deposited TiN, TiAlSiN and TiCrAlSiN coatings on AISI 316 stainless steel fishing net-weaving machine components under dry soft-sliding against nylon fibres. Wear, 390-391, 146-154. https://doi.org/10.1016/j.wear.2017.07.018

[24] Mrkvica, I., Neslusan, M., Cep, R., \& Sleha, V. (2016). Properties and comparisons of PVD coatings. Tehnicki vjesnik-Technical Gazette, 23, 569-574.

https://doi.org/10.17559/TV-20140509105317

\section{Contact information:}

Supakanya KHANCHAIYAPHUM, PhD

Department of Industrial Engineering,

Faculty of Engineering, Khon Kaen University,

Khon Kaen, 40002 Thailand

E-mail:khansupa@yahoo.com

Charnnarong SAIKAEW, Associate Professor, PhD

(Corresponding author)

Department of Industrial Engineering,

Faculty of Engineering, Khon Kaen University,

Khon Kaen, 40002 Thailand

E-mail: charn_sa@kku.ac.th

\section{Surasak SURINPHONG, MS}

NanoShield PVD Hard Coating Co., Ltd.,

Samutprakarn, 10560 Thailand

E-mail: info@nanoshield-pvd.com 